See Article page 152.

\section{Commentary: The search for a breakthrough in tracheal replacement surgery: The good, the bad, and the downright ugly}

\author{
Robert B. Cameron, MD
}

The long-standing search for a tracheal reconstruction substitute, which emanates from the paucity of viable surgical options for many patients with tracheal neoplasms and segmental stenoses, represents a modern-day tracheal surgery quest for the Holy Grail. Approaches have ranged from ill-conceived attempts at allogeneic transplantation ${ }^{1}$ to complex techniques (sometimes mind-boggling) for autologous and allogeneic tissue replacements, ${ }^{2,3}$ and ultimately to primarily technology-driven, tissue-engineered airway substitutes. ${ }^{4}$ Yet real progress and success remain elusive.

At first glance, creation of a tracheal substitute may seem relatively simple; after all, the trachea is just a straight tube. However, this simplistic assessment quickly collapses under the weight of the trachea's complex realities: a microvascular blood supply, the dual rigid and flexible structure, and the critical need for an intact epithelium to serve as both a barrier to infection and a deterrent to granulation and contraction. Fortunately, important aspects of relevant tracheal biology continue to be elucidated (the good). For instance, some critical biological issues, such as chondrocyte proliferation, ${ }^{5}$ the role of mesenchymal stem cells, ${ }^{6}$ the utility of growth factors, ${ }^{7}$ and in vivo (neo)vascularization techniques, ${ }^{8}$ have been explored recently, producing valuable new data and providing a more solid biological basis for future tracheal replacements.

\footnotetext{
From the Division of Thoracic Surgery, Department of Surgery, David Geffen School of Medicine at UCLA and Division of Thoracic Surgery, Department of Surgery and Perioperative Care, West Los Angeles VA Medical Center, Los Angeles, Calif. Disclosures: The author reported no conflicts of interest.

The Journal policy requires editors and reviewers to disclose conflicts of interest and to decline handling or reviewing manuscripts for which they may have a conflict of interest. The editors and reviewers of this article have no conflicts of interest.

Received for publication Nov 27, 2020; revisions received Nov 27, 2020; accepted for publication Dec 15, 2020; available ahead of print Jan 10, 2021.

Address for reprints: Robert B. Cameron, MD, Division of Thoracic Surgery, Department of Surgery, David Geffen School of Medicine, Room 64-132, Box 957313, 10833 Le Conte Ave, Los Angeles, CA 90095-7313 (E-mail: rcameron@ stanfordalumni.org).

JTCVS Open 2021;5:161-2

2666-2736

Copyright (C) 2020 The Authors. Published by Elsevier Inc. on behalf of The American Association for Thoracic Surgery. This is an open access article under the CC BY-NCND license (http://creativecommons.org/licenses/by-nc-nd/4.0/).

https://doi.org/10.1016/j.xjon.2020.12.010
}

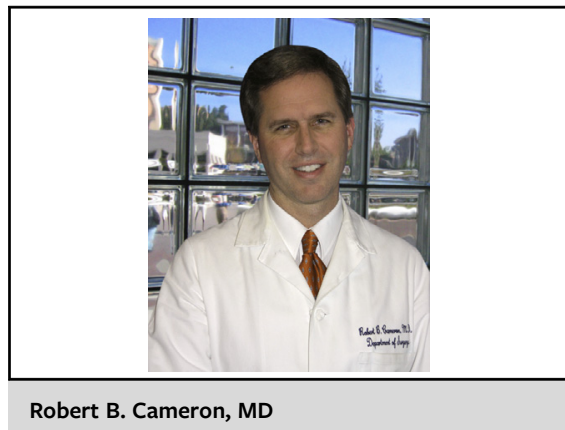

CENTRAL MESSAGE

Research on tracheal reconstruction substitutes should focus less on crude tissueengineered tubes and more on basic biological processes.

Unfortunately, the desperate need for an immediate tracheal replacement has driven research more toward a simplistic tracheal tube model than toward a complex biological organ. Too often, researchers fall prey to the allure of jumping straight to clinical testing using overly simple tubes constructed of biological materials imaginatively envisioned as tracheal replacements (the bad) - a suboptimal process at best that has been facilitated substantially by the development of tissue engineering techniques, such as tissue decellularization and 3-dimensional printing.

In this issue of JTCVS Open, Weber and colleagues ${ }^{4}$ use both of these techniques to generate 2 different types of porcine-derived small intestine submucosa extracellular matrix-covered, size-matched polycaprolactone support scaffolds, one flexible and the other rigid. Although severely limited by the small study size (4 animals), intriguing data from their study suggest that flexible scaffolds (vs rigid) may reduce the incidence of anastomotic dehiscence (the good). Yet overall, there was no functional epithelium or (neo)vascular blood supply. In addition, no dependency of the findings on graft length was determined. Typical issues with granulation, infection, dehiscence, stricture, and obstruction again occurred, but the study does nothing to expand our knowledge regarding the accompanying cellular and molecular biological processes (the bad). Thus in reality, the hasty, small-scale animal testing described essentially eliminates any substantial conclusions and research progress. Finally, owing to the overwhelming desire to identify and test novel tracheal reconstructive options, pressure for progress can lead to premature and 
inappropriate clinical testing of new substitutes not only in animal studies, but also in human clinical trials (the downright ugly). ${ }^{9,10}$ To avoid this, future research should focus less on crude, poorly conceived tissue-engineered tubes and more on the discovery of basic biological aspects of the complex tracheal organ. This approach will lead to the Promised Land and Holy Grail.

\section{References}

1. Levashov YN, Yablonsky PK, Cherny SM, Orlov SV, Shafirovsky BB, Kuznetzov IM. One-stage allotransplantation of thoracic segment of the trachea in a patient with idiopathic fibrosing mediastinitis and marked tracheal stenosis. Eur J Cardiothorac Surg. 1993;7:383-6.

2. Fabre D, Kolb F, Fadel E, Mercier O, Mussot S, Le Chevalier T, et al. Successful tracheal replacement in humans using autologous tissues: an 8-year experience. Ann Thorac Surg. 2013;96:1146-55.

3. Makris D, Holder-Espinasse M, Wurtz A, Seguin A, Hubert T, Jaillard S, et al. Tracheal replacement with cryopreserved allogenic aorta. Chest. 2010;137:60-7.
4. Weber JF, Rehmani SS, Baig MZ, Lebovics R, Raad W, Connery C, et al. Novel composite trachea grafts using 3-dimensional printing. J Thorac Cardiovasc Surg Open. 2021;5:152-60.

5. Walles T, Giere B, Macchiarini P, Mertsching H. Expansion of chondrocytes in a three-dimensional matrix for tracheal tissue engineering. Ann Thorac Surg. 2004; 78:444-8.

6. Seguin A, Baccari S, Holder-Espinasse M, Bruneval P, Carpentier A, Taylor DA, et al. Tracheal regeneration: evidence of bone marrow mesenchymal stem cell involvement. J Thorac Cardiovasc Surg. 2013;145:1297-304.e2.

7. Dikina AD, Strobel HA, Lai BP, Rolle MW, Alsburg E. Engineered cartilaginous tubes for tracheal tissue replacement via self-assembly and fusion of human mesenchymal stem cell constructs. Biomaterials. 2015; $52: 452-62$.

8. Luo X, Liu Y, Zhang Z, Tao R, Liu Y, He A, et al. Long-term functional reconstruction of segmental tracheal defect by pedicled tissue-engineered trachea in rabbits. Biomaterials. 2013;34:3336-44.

9. Fux T, Österholm C, Themudo R, Simonson O, Grinnemo K-H, Corbascio M. Synthetic tracheal grafts seeded with bone marrow cells fail to generate functional tracheae: first long-term follow-up study. J Thorac Cardiovasc Surg. 2020;159:2525-37.e23.

10. The final verdict on Paolo Macchiarini: guilty of misconduct. Lancet. 2018;392:2. 